\title{
Cessões de direitos creditórios dos bancos brasileiros: análise exploratória do impacto no desempenho operacional e financeiro
}

\author{
Brazilian banks' loan sales: an exploratory analysis of the impact on operational and \\ financial performance
}

Cesiones de derechos de crédito de los bancos brasileños: análisis exploratorio del impacto en el rendimiento operativo y financiero

\author{
Alexandre Leite dos Santos \\ Mestre em Administração pela Universidade de Brasília (UnB) \\ Endereço: Condomínio San Diego, Quadra 1, Rua 3, casa 64 \\ CEP: 71680-362 - Brasília/DF - Brasil \\ E-mail: alexandre.santos083@gmail.com \\ Telefone: (61) 3264-4679

\section{Ivan Ricardo Gartner} \\ Doutor em Engenharia de Produção pela Universidade Federal de Santa Catarina (UFSC) \\ Professor Titular do Programa de Pós-Graduação em Administração da Universidade de \\ Brasília (PPGA/UnB) \\ Endereço: Universidade de Brasília, FACE - Departamento de Administração. Campus Darcy \\ Ribeiro, Prédio da FACE, s. B1-47/7 - Asa Norte \\ CEP:70910-900 - Brasília/DF - Brasil \\ E-mail: irgartner@hotmail.com \\ Telefone: (61) 3107-0888
}

Artigo recebido em 06/12/2016. Revisado por pares em 11/04/2018. Reformulado em 10/05/2018. Recomendado para publicação em 15/06/2018 por Carlos Eduardo Facin Lavarda Editor-Chefe). Publicado em 30/06/2018. 


\title{
Resumo
}

As cessões de direitos creditórios expandiram-se no Brasil durante a primeira década dos anos 2000. Embora tenham apresentado modesto crescimento desde então, as vendas de operações de crédito ainda ocorrem, sem que se tenha clareza quanto aos impactos dessa prática sobre o desempenho operacional e financeiro dos bancos nacionais. Com base em informações contábeis compiladas pelo Banco Central do Brasil, cobrindo uma amostra de 192 bancos, no período de 2004 a 2014, este trabalho emprega, de maneira exploratória, a Análise de Componentes Principais (ACP), visando identificar os indicadores mais representativos de características latentes dos bancos atuantes no mercado secundário de créditos. Os resultados apontam os construtos com maior potencial para aplicação em estudos futuros de relações funcionais entre cessão de direitos creditórios e desempenho bancário: Desempenho Operacional, Composição das Receitas não Operacionais, Tipos de Ativos Cedidos, Capacidade de Financiamento via Depósitos, Necessidades de Liquidez e Risco da Carteira de Crédito.

Palavras-chave: Cessão de Direitos Creditórios; Bancos; Índices Financeiros; Análise de Componentes Principais

\begin{abstract}
Loan Sales have expanded in Brazil during the first decade of 2000s. Although they have grown modestly since then, credit portfolio sales still occur, without a clear understanding of their impact over national banks' operational and financial performance. Based on accounting information compiled by the Central Bank of Brazil, over a sample of 192 banks, in the period of 2004 to 2014, this paper uses, in an exploratory manner, Principal Component Analysis (PCA) in order to identify the most representative indicators of latent characteristics of the banks which negotiate in credit secondary markets. The results point the constructs with greatest potential for application in future research concerning functional relationships between loan sales and bank performance: Operational Performance, Mix of Non-Operational Revenues, Types of Loans Sold, Funding Capacity by Deposits, Liquidity Requirements and Credit Portfolio Risk.
\end{abstract}

Keywords: Loan Sales; Banks; Financial measures; Principal Component Analysis

\section{Resumen}

Las cesiones de derechos de crédito se han expandido en Brasil durante la primera década de los años 2000. Aunque tengan presentado un crecimiento moderado desde entonces, todavía se producen las operaciones de venta de créditos, sin tenerse claridad sobre cuáles son los impactos de esta práctica en el rendimiento operacional y financiero de los bancos nacionales. Con base en la información contable recopilada por el Banco Central de Brasil, cubriendo una muestra de 192 bancos, en el período 2004-2014, este trabajo emplea, de manera exploratoria, el Análisis de Componentes Principales (ACP) para identificar los indicadores más representativos de características latentes de los bancos que operan en el mercado secundario de crédito. Los resultados señalan los constructos con mayor potencial para su uso en futuros estudios de las relaciones funcionales entre la cesión de créditos y el rendimiento de los bancos: Rendimiento Operativo, Composición de Los Ingresos no Operativos, Tipos de Activos Cedidos, Capacidad de Financiación por Depósitos, Necesidades de Liquidez y Riesgo de la Cartera de Crédito.

Palabras clave: Cesión de Derechos de Crédito; Bancos; Indices financeiros; Análisis de Componentes Principales 
Cessões de direitos creditórios dos bancos brasileiros: análise exploratória do impacto no desempenho operacional e financeiro

\section{Introdução}

Mercados de crédito eficientes são primordiais para o ensejo do crescimento e do desenvolvimento econômicos. O crédito constitui mola propulsora para investimentos e suporte para o aproveitamento de oportunidades de negócio. Por consequência, provê estímulos ao aumento da produção e da atividade econômica (KEYNES, 1996, p. 107).

Cabe observar, contudo, que nos modernos sistemas de intermediação financeira, as operações de crédito, em especial as realizadas por instituições bancárias, não constituem apenas instrumentos de criação de poder de compra para empreendedores com necessidades imediatas de capital. Em circunstâncias específicas, os ativos representados por tais operações podem constituir em si mesmos os produtos finais a serem transacionados pelos agentes de mercado.

As cessões de direitos creditórios - também denominadas, na regulamentação bancária nacional, operações de venda ou transferência de ativos financeiros - consistem em contratos por meio dos quais um banco qualquer vende a um terceiro uma fração ou todo o direito ao fluxo de caixa proveniente de uma determinada operação de crédito (GORTON; PENNACCHI, 1995, p. 391). Tal definição já traz, implicitamente, a noção de que os fluxos de cessão de direitos creditórios guardam relação direta com o estoque de operações de crédito ativas no sistema financeiro, seja esse estoque mantido por uma única instituição ou por todo um conjunto de bancos.

Entre os anos de 2010 e 2012, foi expressivo o crescimento das operações de cessão de direitos creditórios frente à evolução do volume de crédito total no Brasil, conforme pode ser observado na Figura 1. A partir de então, houve um arrefecimento dessa tendência de crescimento acelerado, cabendo avaliar se tal fato decorreu de limitações desse próprio mercado ou de uma tendência geral da economia, particularmente, do segmento de crédito no país.

Figura 1. Evolução das operações de crédito e das cessões de direitos creditórios no Brasil entre 2004 e 2014.

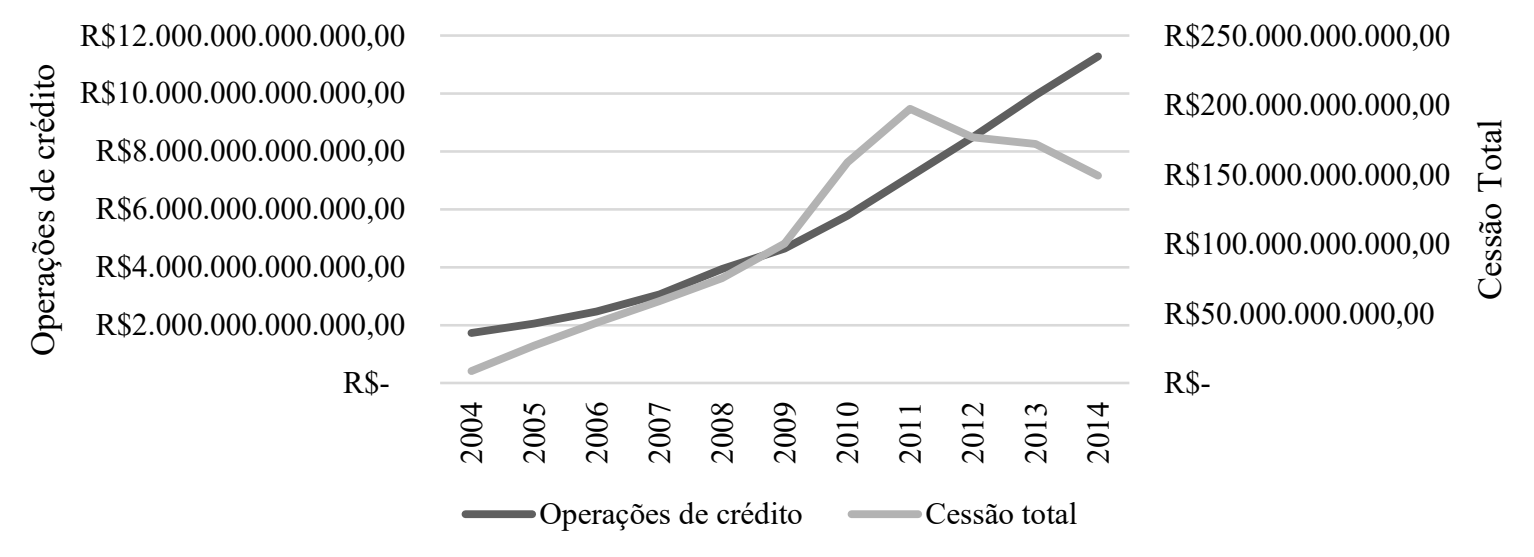

Fonte: Banco Central do Brasil (2015).

Característica particularmente notória das cessões de direitos creditórios realizadas no país concerne às instituições que mais contribuíram, em volume, para o período de rápida expansão dessas operações. Foi, principalmente, entre as instituições bancárias pequenas e médias que se identificaram os principais cedentes, em termos de número de operações realizadas. Apesar disso, a partir da primeira metade de 2015, créditos inadimplentes foram objeto de cessão, sobretudo, pelos bancos públicos, para fins de gestão do risco de suas carteiras (BCB, 2015b, p. 23). 
Há, ainda, outros aspectos das operações da cessão de direitos creditórios, não relacionados apenas à gestão de riscos, com o potencial de impactar o gerenciamento de carteiras de crédito. Entretanto, a definição de quais fatores exercem maior ou menor influência na decisão das instituições financeiras de se inserirem nesse mercado pressupõe a existência de fundamentos teóricos que sirvam de alicerce para a definição de uma relação funcional entre, de um lado, a realização de tais operações, e, de outro, as variáveis ou indicadores financeiros mais adequados para a mensuração do desempenho bancário, seja ele compreendido em termos operacionais ou financeiros.

Nesse sentido, algumas questões permeiam a maior parte da literatura sobre as cessões de direitos creditórios, sendo possível segmentá-la em alguns eixos principais. Em geral, as pesquisas buscam responder por que o mercado secundário de crédito existe, ou seja, o que determina a oferta e a demanda por direitos creditórios (PAVEL; PHILLIS, 1987; PENNACCHI, 1988; CARLSTROM; SAMOLYK, 1995; RIBEIRO; SCHIOZER, 2014; FARRUGGIO; UHDE, 2015; HAN ET AL., 2015), como os negociantes superam problemas de assimetria informacional, de forma a viabilizar o mercado de cessões (PARLOUR; PLANTIN, 2008; ALTMAN ET AL.; 2010) e, mais especificamente, quais os impactos das cessões no que concerne à gestão das carteiras de crédito dos bancos (HAUBRICH; THOMSON, 1996; DAHIYA ET AL., 2003; CATÃO, 2009; DRUCKER; PURI, 2009; BEDENDO; BRUNO, 2012).

É possível identificar, portanto, uma série de fatores potencialmente influentes tanto sobre a decisão de realização das cessões de direitos creditórios quanto na determinação dos montantes envolvidos em tais operações. Em teoria, os bancos podem manipular a composição de suas carteiras de crédito, por meio de negociações no mercado secundário, visando a otimização da estrutura patrimonial (AHN; BRETON; 2014), uma gestão ativa dos riscos da carteira (PAVEL; PHILLIS, 1987; CARDONE-RIPORTELLA ET AL.; 2010; FARRUGGIO; UHDE, 2015), ou a diversificação de atividades e de fontes de financiamento, buscando um aumento da rentabilidade (BANNIER; HÄNSEL, 2008; AFFINITO; TAGLIAFERRI, 2010; CASU ET AL., 2013).

Portanto, um melhor entendimento quanto à forma como as cessões de direitos creditórios se inserem no contexto mais amplo da gestão das carteiras de crédito dos bancos, especificamente no que concerne aos retornos financeiros e aos riscos incorridos na realização de tais operações, pode impactar a tomada de decisões não apenas das próprias instituições bancárias, mas também de seus investidores, credores e reguladores.

Sendo assim, este trabalho busca resposta para a seguinte questão de pesquisa: como a realização de cessões de direitos creditórios se relaciona com outras características determinantes dos perfis e indicadores de desempenho operacional e financeiro dos bancos brasileiros?

Objetiva-se neste trabalho, portanto, identificar, empiricamente, dentre diversos indicadores de desempenho bancário concernentes aos custos de financiamento, à eficiência operacional, à diversificação e liquidez dos ativos, ao risco da carteira de crédito e a outros fatores concernentes à estrutura de capital, quais seriam os construtos mais adequados e significativos para a modelagem de uma relação funcional entre desempenho operacional e financeiro e as operações de cessão de direitos creditórios.

Trata-se, portanto, de uma pesquisa de cunho exploratório. Tal característica faz com que a contribuição do trabalho esteja, primordialmente, na verificação empírica das variáveis mais significativas para cada um dos aspectos das cessões abordados no trabalho, considerandose que as diversas possibilidades anteriormente apontadas na literatura foram definidas e testadas em contextos bastante diferenciados do sistema financeiro nacional. Não obstante, cabe 
Cessões de direitos creditórios dos bancos brasileiros: análise exploratória do impacto no desempenho operacional e financeiro

apontar também a utilidade dos resultados obtidos para a atividade dos órgãos reguladores, mais especificamente, para o Banco Central do Brasil (BCB), haja vista o tema ser objeto de normatização e de fiscalização bancária por parte do órgão supervisor do Sistema Financeiro Nacional.

$\mathrm{O}$ restante do artigo está estruturado em quatro seções. Na próxima, apresenta-se o referencial da pesquisa, tanto teórico quanto teórico-empírico. Na terceira seção, relatam-se os procedimentos metodológicos. Posteriormente, os resultados são expostos e discutidos. Por fim, são tecidas as considerações e conclusões do estudo.

\section{Referencial Teórico}

\subsection{Teoria clássica sobre cessão de direitos creditórios}

Os primeiros trabalhos acadêmicos com foco no tema cessão de direitos creditórios datam do final da década de 1980 (GREENBAUM; THAKOR, 1987; JAMES, 1988; PENNACCHI, 1988). Nesse período, a assimetria informacional entre vendedores e compradores de direitos creditórios e outros fatores que exercem influência sobre os custos de financiamento das instituições financeiras foram apontados na literatura como os principais determinantes do comportamento dos bancos no mercado secundário de crédito.

Enquanto modelos assumindo informação perfeitamente simétrica e ausência de intervenção governamental indicavam que os bancos seriam indiferentes entre financiarem suas operações por meio da captação de depósitos ou da realização de vendas de operações de crédito (GREENBAUM; THAKOR, 1987, p. 386), o relaxamento de tais restrições, bem como a inclusão de outros fatores intervenientes, tais como a participação de seguradoras, indicavam haver certa variabilidade sobre qual seria a estratégia de financiamento mais adequada, a depender do cenário.

Nessa linha, buscava-se avaliar se, como, e em quais contextos a mitigação dos problemas de assimetria informacional entre instituições bancárias poderia tornar viável a utilização das operações de cessão de créditos na redução dos custos de financiamento das operações bancárias.

Antes do estudo mais aprofundado dessa questão, era disseminado o entendimento de que empréstimos bancários não constituíam ativos negociáveis, devido, sobretudo, a problemas de risco moral. Argumentava-se que, uma vez transferida por completo a exposição às perdas decorrentes de uma eventual inadimplência dos tomadores, os bancos não teriam mais quaisquer incentivos para manterem o monitoramento das operações e para continuarem efetuando análises quanto ao risco de crédito e ao desempenho financeiro das contrapartes cujas obrigações foram negociadas (PENNACCHI, 1988, p. 377).

Sendo assim, para que os bancos tivessem os incentivos corretos para manter as atividades de avaliação de riscos e de monitoramento de seus empréstimos, acreditava-se ser necessária a retenção de ao menos uma parcela do risco de inadimplência relativo a tais operações, mesmo depois de cedidas (PENNACCHI, 1988, p. 389). Por outro lado, a capacidade 36 de um banco qualquer de vender seus direitos creditórios para terceiros dependeria da percepção dos eventuais compradores quanto à efetividade dos incentivos postos para a instituição bancária em favor dessa continuidade no monitoramento das operações cedidas (JAMES, 1988, p. 399).

A solução para tal impasse consistiria no estabelecimento de alguma forma de contrato entre vendedores e compradores, por meio do qual a estrutura de incentivos para a repartição dos riscos poderia ser melhor delineada e assegurada. Uma vez elaborado tal contrato, se faria 
possível que bancos inseridos em ambientes de alta competitividade na captação de depósitos, ou sujeitos a restrições regulatórias, tais como requerimentos de reservas e de capital, reduzam seus custos de financiamento por meio das vendas de operações de crédito (PENNACCHI, 1988, p. 384).

Todavia, ainda que restrições regulatórias possam motivar as vendas de créditos, há dinâmicas do próprio mercado que talvez sejam mais relevantes na indução dos bancos à realização de tais operações.

A assimetria informacional entre cedentes e cessionários levou diversas instituições a perceberem na originação e distribuição de operações de crédito uma atividade lucrativa, caso inexistente qualquer obrigatoriedade de manutenção das operações em carteira até o vencimento. Do lado da demanda, um mercado de venda e transferência de créditos permite a bancos com folga de capital adquirirem operações avaliadas como potencialmente lucrativas, originadas por bancos cuja estrutura de capital não lhes permitiria assumir riscos adicionais (CARLSTROM; SAMOLIK, 1995, p. 637).

\subsection{Referencial teórico-empírico}

Pavel e Phillis (1987) apresentam um dos primeiros trabalhos empíricos com foco no tema cessão de direitos creditórios. Utilizando dados de cessões realizadas no sistema bancário norte-americano entre 1983 e 1985, os autores testam modelos cujo intuito é identificar quais os principais motivos a fazer com que os bancos vendam parte de suas carteiras de crédito (PAVEL; PHILLIS, 1987, p. 5). Apesar de restrições regulatórias influenciarem a participação nesse mercado, vantagens comparativas na originação e serviço das operações de crédito foram apontadas como o principal determinante da probabilidade de os bancos efetuarem cessões, bem como dos montantes a serem cedidos. Ademais, identificaram uma tendência de que os bancos comecem a vender parte de suas carteiras de crédito quando suas razões de capital estão baixas ou quando as operações levadas a prejuízo estão excessivamente altas (PAVEL; PHILLIS, 1987, p. 12).

Gorton e Pennacchi (1995, p. 395), apontando os possíveis motivos para um aumento do volume de operações de cessão de créditos - incremento dos custos de financiamento interno dos bancos via depósitos ou oportunidade de diversificação da carteira de empréstimos elaboram um modelo de garantias contratuais implícitas entre cedentes e cessionários de forma a alinhar os incentivos para a realização de operações de cessão.

O modelo foi testado em uma amostra de mais de 800 operações de cessão realizadas entre 1986 e 1987 por um único banco norte-americano, e o resultado que encontram é consistente com o modelo, confirmando a previsão dos autores de que os bancos tendem a manter os empréstimos de maior grau de risco em sua carteira quando empreendem operações de cessão. Nesse modelo, a preferência por transferir os ativos com menor risco de crédito decorreria do menor prêmio exigido pelos compradores na aquisição desses ativos e pela premissa de que os vendedores oferecem garantias implícitas, se comprometendo a recomprar créditos eventualmente inadimplentes (GORTON; PENNACCHI, 1995, p. 408).

Haubrich e Thomson (1996), em linha com o modelo de avaliação dos custos de financiamento bancário de Pennacchi (1988), também discutem os determinantes para a participação dos bancos no mercado secundário de operações de crédito. $O$ porte das instituições, suas estruturas de capital e de risco, bem como estratégias de financiamento e investimento, são todos apontados como fatores determinantes significativos da participação dos bancos nas operações de cessão de direitos creditórios (HAUBRICH; THOMSON, 1996, p. 149). 
Cessões de direitos creditórios dos bancos brasileiros: análise exploratória do impacto no desempenho operacional e financeiro

Assim como Gorton e Pennacchi (1995) e Haubrich e Thomson (1996), Demsetz (2000, p. 198) avalia possíveis motivações para as cessões de crédito. Para tanto, a autora testa a validade de duas hipóteses. A primeira sugere que, enquanto há bancos que apresentam uma vantagem comparativa na originação de operações de crédito, há bancos com vantagem comparativa no financiamento por meio da aquisição desse tipo de operação. Os primeiros tendem a atuar mais frequentemente como cedentes, enquanto os segundos como cessionários. A segunda hipótese explorada diz respeito à diversificação de carteiras. Bancos que por algum motivo apresentam restrições ou dificuldades para diversificar suas carteiras de crédito por conta própria tenderiam a fazer isso por meio de atuação no mercado de cessões de direitos creditórios.

Fazendo algo até então atípico na literatura, Demsetz (2000, p. 203) aponta quatro posicionamentos possíveis para os bancos frente às cessões de direitos creditórios e avalia, separadamente, bancos que atuam apenas como cedentes, bancos que atuam apenas como cessionários, bancos que atuam nas duas posições e bancos que não têm qualquer participação no mercado secundário de créditos. Os resultados obtidos pela autora apontam que cada um desses grupos responde de uma forma específica quando consideradas as hipóteses testadas.

Parlour e Plantin $(2008$, p. 27) testaram as hipóteses de que os bancos operam no mercado secundário de créditos basicamente para reestruturarem a composição de suas carteiras ou para tirarem proveito de negociações baseadas na posse de informações privilegiadas. Os autores constataram que o fato de as operações ocorrerem por um motivo ou pelo outro influenciaria diretamente a liquidez dos ativos sendo transacionados, sendo que, em geral, instituições com carteiras de crédito mais diversificadas tendem a dispor de maior liquidez quando da venda de seus créditos (PARLOUR; PLANTIN, 2008, p. 40).

Também tendo como pano de fundo a avaliação de problemas de assimetria de informações, Altman, Gande e Saunders (2010, p. 764), comparando o mercado secundário de títulos com o de operações de crédito, evidenciam que este é relativamente mais eficiente do ponto de vista de disseminação de informações, e que, mesmo depois de cedidos os créditos, os bancos continuam exercendo importante função de monitores do desempenho das operações.

Outra questão relevante para investigação no âmbito das operações de cessão de crédito diz respeito à qualidade dos ativos sendo negociados. A venda de operações de crédito por vezes é vista com desconfiança por eventuais compradores, haja vista a possibilidade de se tratar de uma instituição financeira tentando retirar de sua carteira operações com baixa qualidade creditícia. Nesse sentido, Dahiya, Puri e Saunders (2003, p. 576) constataram que o anúncio de oferta de operações de crédito no mercado secundário pode, de fato, representar uma sinalização negativa quanto à qualidade dos créditos negociados. Por meio de uma análise do subsequente desempenho dos devedores que tiveram seus empréstimos vendidos, os autores verificaram diversos casos de falência dos tomadores e sua consequente inadimplência pouco depois de seus créditos terem sido negociados.

Drucker e Puri (2009, p. 2852), explorando ampla base de operações de cessão realizadas no mercado norte-americano entre 1998 e 2005, verificaram que $60 \%$ dos empréstimos eram cedidos em até um mês após sua originação, e que $90 \%$ era cedido dentro de um ano. Ademais, encontraram evidências de que as cessões são frequentemente utilizadas como forma de gerenciamento do risco de crédito pelos bancos e que isso de certa forma é positivo para os tomadores, pois os clientes cujos empréstimos são cedidos apresentam maior probabilidade de conseguirem tomar crédito novamente com os mesmos bancos no futuro, sugerindo que o sucesso de operações cedidas levaria a um fortalecimento da relação entre a instituição financeira e seu cliente (DRUCKER; PURI, 2009, p. 2864). 
Na mesma linha de análise de risco em que seguiram Drucker e Puri (2009), Bedendo e Bruno (2012) avaliaram o uso de instrumentos de transferência de risco de crédito - cessão de direitos creditórios, securitização e derivativos de crédito - durante os anos de 2007 a 2009 no mercado norte-americano. Verificou-se que $80 \%$ das instituições financeiras que transferiram parcela de suas exposições a risco no período utilizaram apenas um dos três instrumentos estudados. As cessões de direitos creditórios se destacaram como o instrumento mais utilizado em volume, seja individualmente ou em conjunto com outros instrumentos, principalmente quando considerados a faixa de bancos de menor porte da amostra (BEDENDO; BRUNO, 2012, p. 3263).

Os achados de Bedendo e Bruno (2012) são consistentes com o modelo teórico desenvolvido por Parlour e Winton (2013). Embora neste modelo as cessões de crédito sejam comparadas apenas aos derivativos de crédito, os autores demonstram como, uma vez consideradas questões reputacionais decorrentes da iteração das relações entre cedentes e cessionários, o uso das cessões de direitos creditórios como instrumento mitigador apresenta vantagens sobre o uso de derivativos de crédito quando se trata de créditos de risco mais elevado (PARLOUR; WINTON, 2013, p. 41).

Ahn e Breton (2014, p. 202) constatam que a possibilidade de realização de cessões e securitizações suaviza a competição no mercado primário de crédito e possibilitam maiores lucros aos bancos na originação das operações. Por sua vez, Han, Park e Pennacchi (2015, p. 1288) avaliam como os impostos incidentes sobre os rendimentos bancários impactam o volume de cessões de crédito, tendo constatado que, quanto maior a incidência de impostos, maior o número de operações cedidas, especialmente por bancos que, conforme a hipótese de vantagem comparativa testada em outros trabalhos (DEMSETZ, 2000), apresentam maiores oportunidades de originação de novas operações de crédito e maior restrição na captação de novos depósitos.

No que diz respeito à produção acadêmica nacional, Ribeiro e Schiozer (2014, p. 525) mostraram haver uma relação positiva entre uma maior restrição de capital - próprio e de terceiros - e a expansão das operações de cessão de direitos creditórios realizadas pelos bancos brasileiros. Por sua vez, Catão (2009, p. 343) mostrou haver relação entre a securitização de recebíveis e uma piora na carteira de crédito dos bancos brasileiros, bem como redução da alavancagem e aumento da liquidez.

Já no contexto dos trabalhos sobre securitização, cabe destacar como úteis, para os fins desta pesquisa, trabalhos que buscaram determinar os principais fundamentos econômicos e motivadores para a realização dessas operações pelos bancos, por coincidirem, em grande medida, com as razões apontadas para a cessão de direitos creditórios. Esse é o caso por exemplo, dos trabalhos de Affinito e Tagliaferri (2010), Cardone-Riportella, SamaniegoMedina e Trujillo-Ponce (2010) e de Farruggio e Uhde (2015), cujas análises focam, respectivamente, o mercado italiano, o mercado espanhol e o mercado da União Europeia.

Por sua vez, Casu et al. (2013) buscam verificar se a participação em operações de securitização de fato exerce um impacto significativo sobre o desempenho dos bancos. Para tanto, analisam uma extensiva lista de variáveis abrangendo diversos aspectos da atividade bancária possivelmente afetados pelas securitizações, tais como a estrutura dos balanços patrimoniais, composição das carteiras de crédito, medidas de risco e composição do capital regulatório, custos de financiamento e desempenho operacional, a fim de procederem à uma comparação entre bancos securitizadores e não securitizadores (CASU ET AL., 2013, p. 1631). 
Cessões de direitos creditórios dos bancos brasileiros: análise exploratória do impacto no desempenho operacional e financeiro

\section{Metodologia da Análise Empírica}

\subsection{Fonte de dados e plano amostral}

Todos os dados coletados para esta pesquisa foram obtidos na página do Banco Central do Brasil (BCB, 2015a) na internet. A base construída compreende todas as contas dos grupos Ativo, Passivo, Resultado da Intermediação Financeira e Resultado Líquido, disponíveis na subseção "50 maiores bancos", da seção "informações para análise econômico-financeira". Os dados são trimestrais e se referem ao período compreendido entre os anos de 2004 e 2014.

A seleção dos bancos para a amostra se baseou na subdivisão em Tipos de Consolidado Bancário feita pelo Banco Central do Brasil, tendo em vista incluir apenas aquelas instituições que, de alguma forma, podem ter participação no mercado de cessão de direitos creditórios. Sendo assim, trabalhou-se com os Consolidados Bancários I e II, os quais, segundo a definição do $\mathrm{BCB}$, incluem instituições financeiras do tipo banco múltiplo - com ou sem carteira comercial -, caixa econômica e bancos de investimento, bem como conglomerados bancários que incluem em sua composição ao menos um banco comercial, múltiplo ou de investimento. Dentro desses critérios, foram listados 241 bancos no período em análise.

Todavia, uma vez identificados casos em que a indisponibilidade de dados acabava por inviabilizar o cálculo das variáveis do estudo, os respectivos bancos foram eliminados da base. Tal procedimento levou à exclusão de 49 instituições. Dessa forma, ao final, resultou em 192 o número de bancos na amostra. A Tabela 1 apresenta a estatística descritiva dos dados.

Tabela 1 - Estatística descritiva das principais contas coletadas no site do Banco Central do Brasil

\begin{tabular}{ccccc}
\hline R\$ mil & Mínimo & Máximo & Média & Desvio padrão \\
\hline Ativo Total & 17.034 & 1.291 .559 .805 & 28.684 .028 & 116.367 .131 \\
Depósito Total & 0 & 487.446 .674 & 10.445 .601 & 44.122 .745 \\
Operações de crédito e arrendamento mercantil & 0 & 619.697 .634 & 10.712 .168 & 47.354 .161 \\
Coobrigações em cessões de crédito & 0 & 17.769 .172 & 230.454 & 1.365 .810 \\
Receitas -- Operações de crédito & -61.838 & 43.669 .016 & 767.765 & 3.167 .326 \\
Receitas -- vendas ou transf. de ativos financeiros & 0 & 893.610 & 1.934 & 26.339 \\
Despesas -- vendas ou transf. de ativos financeiros & -2.348 .044 & 845.154 & -2.886 & 60.330 \\
Resultado operacional & -25.935 .822 & 14.528 .913 & 165.637 & 896.954 \\
Resultado não operacional & -1.936 .498 & 18.293 .249 & 16.844 & 321.621 \\
Lucro Líquido & -1.460 .594 & 10.311 .204 & 149.820 & 682.366 \\
\hline
\end{tabular}

Fonte: Banco Central do Brasil (2015a)

Com o intuito de melhor adequar os dados à técnica estatística que viria a ser aplicada, a Análise de Componentes Principais, foi realizada, previamente aos testes, a normalização de todas as variáveis, submetendo-se o conjunto de dados à subtração de sua média e posterior divisão pelo desvio padrão. Ademais, por se ter como um dos principais motivadores para a aplicação da referida técnica a busca por padrões comuns de variabilidade entre as variáveis, os dados foram submetidos ao processo de winsorização, ao nível de $1 \%$, a fim de que a influência de outliers sobre os resultados fosse minimizada.

\subsection{Variáveis em estudo}

Uma vez coletados os dados, foram calculados diversos índices financeiros e outros indicadores de evolução das contas ao longo do período. Entre outras, foram capturadas informações concernentes ao volume e à taxa de crescimento dos ativos dos bancos, medidas 
de liquidez e de capital, fluxos da carteira de crédito, retornos sobre ativos e patrimônio líquido e a composição das fontes de receita com intermediação financeira.

De maneira geral, a fundamentação dos índices e demais indicadores apurados é dada por Casu et al. (2013, p. 1649). Entretanto, a indisponibilidade de informações necessárias para a exata replicação de todos os índices da referida pesquisa levou, em diversas ocasiões, à utilização de proxies. Foi o caso, por exemplo, da substituição de receitas e despesas com juros por dados referentes a receitas e despesas de intermediação financeira.

Ao total, foram apuradas 25 variáveis, conforme disposto na Tabela 2 . O primeiro grupo, Estrutura do Balanço Patrimonial, é constituído por 9 (nove) índices. O segundo grupo, Desempenho Operacional, e o terceiro, Receitas de Intermediação Financeira, são compostos por 6 (seis) e 7 (sete) índices, respectivamente. Por fim, os grupos Medida de Risco e Custos de Financiamento agregam uma variável cada.

Tabela 2- Definição e construção das variáveis

\begin{tabular}{|c|c|c|}
\hline $\begin{array}{c}\text { Variável } \\
\end{array}$ & Definição & Construção \\
\hline \multicolumn{3}{|l|}{ Estrutura do balanço patrimonial } \\
\hline w01Ativototalp & Ativo total & Ativo total \\
\hline w01RzLiquidezp & Razão de liquidez & $\begin{array}{c}\text { (Disponibilidades + Aplicações } \\
\text { Financeiras + TVM e Derivativos) / } \\
\text { Ativo total }\end{array}$ \\
\hline w01RzCartNegAtivotp & Razão da carteira de negociação & $\begin{array}{c}\text { (Aplicações interfinanceiras + TVM e } \\
\text { Derivativos) / Ativo total }\end{array}$ \\
\hline w01RzCredArrAtivotp & Razão de operações de concessão & $\begin{array}{c}\text { Operações de crédito e arrendamento } \\
\text { mercantil / Ativo total }\end{array}$ \\
\hline w01RzDepositotp & Razão de depósitos & Depósito Total / Ativo total \\
\hline w01RzCredArrDepostp & Razão concessão/depósitos & $\begin{array}{c}\text { Operações de crédito e arrendamento } \\
\text { mercantil / Depósito total }\end{array}$ \\
\hline w01RzCapitalp & Razão de capital & Patrimônio Líquido / Ativo total \\
\hline w01CrescOpCredp & $\begin{array}{c}\text { Crescimento das operações de } \\
\text { crédito }\end{array}$ & $\begin{array}{l}\text { Taxa de crescimento das operações de } \\
\text { crédito }\end{array}$ \\
\hline w01CrescAtivosp & Crescimento dos ativos & Taxa de crescimento dos ativos \\
\hline w01FluxoCessaop & Fluxo de Cessões de Crédito & $\begin{array}{c}\text { Coobrigações em cessões de crédito/ } \\
\text { Operações de crédito e } \\
\text { arrendamento mercantil }\end{array}$ \\
\hline \multicolumn{3}{|l|}{ Desempenho operacional } \\
\hline w01ROAp & Retorno sobre os ativos & Lucro Líquido / Ativo total \\
\hline w01ROEp & Retorno sobre o patrimônio líquido & Lucro Líquido / Patrimônio Líquido \\
\hline w01HHIReceitastp & Índice HHI para a Receita Total & $\begin{array}{c}\text { (Receita de operações de crédito / } \\
\text { Receita Total })^{2}+(\text { Receita de } \\
\text { operações de arrendamento } \\
\text { mercantil / Receita Total })^{2}+ \\
(\text { Receita de operações com TVMs / } \\
\text { Receita Total })^{2}+(\text { Receita de } \\
\text { operações com derivativos / Receita } \\
\text { Total })^{2}+(\text { Receita de operações de } \\
\text { câmbio / Receita Total })^{2}+(\text { Receita } \\
\text { com aplicações compulsórias / } \\
\text { Receita Total })^{2}+(\text { Receita de venda } \\
\text { ou transferência de ativos } \\
\text { financeiros / Receita Total })^{2}+ \\
\text { (Receita de prestação de serviços / } \\
\text { Receita Total })^{2}+(\text { Rendas de tarifas } \\
\text { bancárias / Receita Total })^{2}+ \\
\text { (Resultado de participação em } \\
\text { coligadas / Receita Total })^{2}+(\text { Outras } \\
\text { receitas operacionais / Receita } \\
\text { Total })^{2}\end{array}$ \\
\hline
\end{tabular}


Cessões de direitos creditórios dos bancos brasileiros: análise exploratória do impacto no desempenho operacional e financeiro

\begin{tabular}{|c|c|c|}
\hline w01RzRecOpNIntResOpp & $\begin{array}{c}\text { Receitas operacionais não } \\
\text { intermediação / resultado } \\
\text { operacional }\end{array}$ & $\begin{array}{c}\text { (Receita de prestação de serviços }+ \\
\text { Rendas de tarifas bancárias }+ \\
\text { Resultado de participação em } \\
\text { coligadas + Outras receitas } \\
\text { operacionais) / Resultado } \\
\text { Operacional } \\
\end{array}$ \\
\hline w01MargemFinp & Margem financeira & $\begin{array}{c}\text { Total das receitas de intermediação } \\
\text { financeira / Ativo total }\end{array}$ \\
\hline w01RzDespOpNIntResOpp & $\begin{array}{c}\text { Despesas operacionais não } \\
\text { intermediação / resultado } \\
\text { operacional }\end{array}$ & $\begin{array}{c}\text { (Despesas de Pessoal + Despesas } \\
\text { Administrativas + Despesas } \\
\text { Tributárias + Outras Despesas } \\
\text { Operacionais) / Resultado } \\
\text { Operacional }\end{array}$ \\
\hline \multicolumn{3}{|l|}{ Receita de intermediação financeira } \\
\hline w01RzRecCreRecIntp & Operações de crédito & $\begin{array}{c}\text { Receita de operações de crédito / Total } \\
\text { da receita de intermediação } \\
\text { financeira } \\
\end{array}$ \\
\hline w01RzRecArrRecIntp & Arrendamento Mercantil & $\begin{array}{c}\text { Receita de operações de arrendamento } \\
\text { mercantil / Total da receita de } \\
\text { intermediação financeira }\end{array}$ \\
\hline w01RzRecTVMRecIntp & Títulos e Valores Mobiliários & $\begin{array}{c}\text { Receita de operações com títulos e } \\
\text { valores mobiliários / Total da } \\
\text { receita de intermediação financeira }\end{array}$ \\
\hline w01RzRecDerRecIntp & Derivativos & $\begin{array}{c}\text { Receita de operações com derivativos / } \\
\text { Total da receita de intermediação } \\
\text { financeira }\end{array}$ \\
\hline w01RzRecCamRecIntp & Câmbio & $\begin{array}{c}\text { Receita de operações de câmbio / Total } \\
\text { da receita de intermediação } \\
\text { financeira } \\
\end{array}$ \\
\hline w01RzRecAplCompRecIntp & Aplicações Compulsórias & $\begin{array}{c}\text { Receita com aplicações compulsórias / } \\
\text { Total da receita de intermediação } \\
\text { financeira }\end{array}$ \\
\hline w01RzRecVenTraRecIntp & $\begin{array}{l}\text { Venda ou transferência de ativos } \\
\text { financeiros }\end{array}$ & $\begin{array}{c}\text { Receita de operações de venda ou } \\
\text { transferência de ativos financeiros / } \\
\text { Total da receita de intermediação } \\
\text { financeira }\end{array}$ \\
\hline w01HHIRecIntFinp & $\begin{array}{l}\text { Índice HHI da receita de } \\
\text { intermediação financeira }\end{array}$ & $\begin{array}{c}\text { (Receita de operações de crédito / Total } \\
\text { da receita de intermediação) })^{2}+ \\
\text { (Receita de operações de } \\
\text { arrendamento mercantil / Total da } \\
\text { receita de intermediação) })^{2}+ \\
\text { (Receita de operações com TVMs / }^{\text {Total da receita de intermediação) }}{ }^{2} \\
\text { + (Receita de operações com } \\
\text { derivativos / Total da receita de } \\
\text { intermediação) })^{2}+(\text { Receita de } \\
\text { operações de câmbio / Total da } \\
\text { receita de intermediação) })^{2}+ \\
\text { (Receita com aplicações } \\
\text { compulsórias / Total da receita de } \\
\text { intermediação) })^{2}+(\text { Receita de venda } \\
\text { ou transferência de ativos } \\
\text { financeiros / Total da receita de } \\
\text { intermediação) })^{2} \\
\end{array}$ \\
\hline \multicolumn{3}{|l|}{ Medida de risco } \\
\hline w01RzProvisoesp & Razão de provisões & $\begin{array}{l}\text { Provisão para CL / Operações de } \\
\text { Crédito e Arrendamento Mercantil }\end{array}$ \\
\hline \multicolumn{3}{|l|}{ Custo de financiamento } \\
\hline w01RzDespCapDespIntp & $\begin{array}{l}\text { Despesas de captação/total das } \\
\text { despesas de intermediação }\end{array}$ & $\begin{array}{l}\text { Total das despesas de captação no } \\
\text { mercado / total das despesas de } \\
\text { intermediação financeira }\end{array}$ \\
\hline
\end{tabular}

Fonte: Elaborada pelos autores 


\subsection{Técnica de Análise}

Por se buscar uma representação simplificada para um amplo conjunto de variáveis, em princípio, intercorrelacionadas, emprega-se neste estudo a técnica de Análise de Componentes Principais (ACP). Trata-se de uma técnica exploratória por meio da qual é possível se chegar à definição de um número menor de novas variáveis não correlacionadas - os componentes principais - minimizando, nesse processo, a perda de informação (AFIFI; MAY; CLARK, 2012 , p. 357). O que se busca com tal técnica é a identificação dos construtos fundamentais ou dimensões assumidas como inerentes às variáveis originais.

O uso da técnica de Análise de Componentes Principais para identificação de padrões e características fundamentais em dados bancários encontra respaldo na literatura. Canbas, Cabuk e Kilic (2005, p. 532) defendem ser possível utilizar a ACP com o intuito de identificar padrões de relacionamento subjacentes entre razões financeiras e o fazem buscando determinar os fatores mais importantes para explicação de mudanças nas condições financeiras dos bancos que, no limite, podem leva-los à falência.

Por sua vez, Shih, Zhang e Liu (2007, p. 19) empreendem uma análise comparativa do desempenho financeiro dos bancos chineses a partir de quatro indicadores construídos por meio de aplicação da ACP a uma série de dados coletados do Banco Central Chinês. Champagne e Coggins (2012, p. 1439), fazem uso da ACP para analisar como problemas de assimetria de informação específicos de empréstimos sindicalizados afetam os spreads dessas operações. Klomp e Haan (2012, p. 3200) avaliam o impacto da regulação e supervisão bancárias sobre o risco incorrido pelos bancos da OCDE utilizando regressões quantílicas, mas, para tanto, utilizam previamente a ACP para definição de proxies das variáveis representativas dos conceitos de regulação e supervisão. Creel, Hubert e Labondance $(2015$, p. 28) elaboram um índice de estabilidade financeira a partir da aplicação da ACP sobre um conjunto de razões financeiras dos países da União Europeia, buscando estabelecer uma relação entre performance macroeconômica e estabilidade financeira.

A fim de verificar a adequação da ACP para o presente estudo, a base de dados foi inicialmente submetida ao teste de esfericidade de Bartlett e ao teste Kaiser-Meyer-Olkin para medida de adequação da amostra (KMO). Ambos resultaram em valores considerados adequados para aplicação de técnicas multivariadas de análise fatorial. $\mathrm{O}$ primeiro indicou a possibilidade de rejeição da hipótese nula de que as variáveis não são correlacionadas, enquanto o segundo teve como resultado o valor de 0,638 , ficando acima, portanto, do nível considerado aceitável $(\mathrm{KMO}>0,5)$ para fins de aplicação da ACP.

\section{Resultados e Análise Empírica}

Após análise inicial dos componentes principais da amostra, optou-se pela retenção dos primeiros nove fatores para prosseguimento do estudo, em consonância com o critério de Kaiser, o qual define, como critério de corte, a manutenção dos fatores cujos autovalores (ou raízes latentes) sejam maiores ou iguais a 1,0. Apesar de se tratar de um critério arbitrário para determinação da significância dos autovalores, verificou-se, adicionalmente, que, mantidos apenas os nove primeiros fatores, já se faria possível explicar, aproximadamente, $80 \%$ da variância das variáveis, conforme Tabela 3 . 
Cessões de direitos creditórios dos bancos brasileiros: análise exploratória do impacto no desempenho operacional e financeiro

Tabela 3 - Componentes Principais

\begin{tabular}{ccccc}
\hline Componente & Autovalor & Diferença & \multicolumn{1}{c}{ Proporção } & \multicolumn{1}{c}{ Acumulado } \\
\hline Comp1 & 5.51914 & 2.47232 & 0.2208 & 0.2208 \\
Comp2 & 3.04683 & .306532 & 0.1219 & 0.3426 \\
Comp3 & 2.74029 & .863201 & 0.1096 & 0.4523 \\
Comp4 & 1.87709 & .248984 & 0.0751 & 0.5273 \\
Comp5 & 1.62811 & .0403897 & 0.0651 & 0.5925 \\
Comp6 & 1.58772 & .315078 & 0.0635 & 0.6560 \\
Comp7 & 1.27264 & .0661158 & 0.0509 & 0.7069 \\
Comp8 & 1.20653 & .162153 & 0.0483 & 0.7551 \\
Comp9 & $\mathbf{1 . 0 4 4 3 7}$ & $\mathbf{. 2 0 2 0 2 4}$ & $\mathbf{0 . 0 4 1 8}$ & $\mathbf{0 . 7 9 6 9}$ \\
Comp10 & .84235 & .184329 & 0.0337 & 0.8306 \\
\hline
\end{tabular}

Fonte: Elaborada pelos autores

Em seguida, os componentes foram rotacionados, inicialmente, pelo método ortogonal Varimax, a fim de se verificar as cargas fatoriais significantes para cada uma das variáveis. Nenhuma carga fatorial significante foi identificada no primeiro fator. Ademais, 11 das 25 variáveis não apresentaram carga fatorial significante em qualquer componente. Entre as outras 14, nenhuma apresentou cargas fatoriais cruzadas, de forma que cada uma foi alocada em tãosomente um componente, conforme Tabela 4.

Tabela 4 - Cargas fatoriais rotacionadas

\begin{tabular}{|c|c|c|c|c|c|c|c|c|c|}
\hline Variável & Comp1 & Comp2 & Comp3 & Comp4 & Comp5 & Comp6 & Comp7 & Comp8 & Comp9 \\
\hline w01Ativoto $\sim p$ & & -0.5147 & & & & & & & \\
\hline w01RzRecAp $\sim p$ & & 0.5241 & & & & & & & \\
\hline w01RzDepos $\sim p$ & & & 0.5980 & & & & & & \\
\hline w01RzCre $\sim$ stp & & & -0.5095 & & & & & & \\
\hline w01ROAp & & & & 0.6420 & & & & & \\
\hline w01ROEp & & & & 0.6182 & & & & & \\
\hline w01RzRecOp p p & & & & & -0.7044 & & & & \\
\hline w01RzDespO $\sim p$ & & & & & 0.6995 & & & & \\
\hline w01RzRecDe p p & & & & & & -0.7373 & & & \\
\hline w01RzProvi p p & & & & & & & 0.6390 & & \\
\hline w01FluxoCe $\sim p$ & & & & & & & -0.5066 & & \\
\hline w01CrescOp $\sim p$ & & & & & & & & 0.6792 & \\
\hline w01CrescAt $\sim p$ & & & & & & & & 0.6958 & \\
\hline w01RzRecCa p & & & & & & & & & -0.8856 \\
\hline w01RzLiqui $\sim p$ & & & & & & & & & \\
\hline w01RzCartN $\sim p$ & & & & & & & & & \\
\hline w01RzCre $\sim$ otp & & & & & & & & & \\
\hline w01HHIRece $\sim p$ & & & & & & & & & \\
\hline w01HHIRecI p & & & & & & & & & \\
\hline w01RzRecCr p p & & & & & & & & & \\
\hline w01RzRecAr $\sim p$ & & & & & & & & & \\
\hline w01RzRecTV $\sim p$ & & & & & & & & & \\
\hline w01MargemF $\sim p$ & & & & & & & & & \\
\hline w01RzCapit $\sim$ p & & & & & & & & & \\
\hline w01RzDespC $\sim p$ & & & & & & & & & \\
\hline
\end{tabular}

Outros métodos de rotação, tanto ortogonais quanto oblíquos, foram testados. Todavia, nenhum ofereceu resposta significativamente diferente da rotação pelo método Varimax. Dado o quadro com elevado número de variáveis não explicadas pela análise, optou-se pela reespecificação do modelo e a realização do cálculo de uma nova matriz de componentes, mantendo-se apenas as 14 variáveis com cargas fatoriais significantes do primeiro teste. Novamente em atenção ao critério de Kaiser, foram retidos 6 componentes, o que reduziu o nível de explicação da variância para próximo dos $70 \%$, conforme resultados da Tabela 5. 
Tabela 5 -Componentes Principais do Modelo 2

\begin{tabular}{ccccc}
\hline Componente & Autovalor & Diferença & Proporção & Acumulado \\
\hline Comp1 & 2.71885 & .883061 & 0.1942 & 0.1942 \\
Comp2 & 1.83579 & .165926 & 0.1311 & 0.3253 \\
Comp3 & 1.66986 & .17755 & 0.1193 & 0.4446 \\
Comp4 & 1.49231 & .233082 & 0.1066 & 0.5512 \\
Comp5 & 1.25923 & .213503 & 0.0899 & 0.6411 \\
Comp6 & $\mathbf{1 . 0 4 5 7 3}$ & $\mathbf{. 0 4 5 9 7 9 6}$ & $\mathbf{0 . 0 7 4 7}$ & $\mathbf{0 . 7 1 5 8}$ \\
Comp7 & .999751 & .0827392 & 0.0714 & 0.7873 \\
Comp8 & .917012 & .259577 & 0.0655 & 0.8528 \\
\hline
\end{tabular}

Fonte: Elaborada pelos autores

Após a rotação ortogonal dos componentes pelo método Varimax, todas as variáveis apresentaram cargas fatoriais significantes em algum dos seis componentes, não tendo sido verificadas cargas cruzadas. A distribuição das variáveis na solução fatorial se mostrou uniforme, de maneira que cada um dos seis componentes comportou exatamente duas variáveis, conforme resultados dispostos na Tabela 6 .

Tabela 6 -Cargas fatoriais rotacionadas do Modelo 2

\begin{tabular}{|c|c|c|c|c|c|c|}
\hline Variável & Comp1 & Comp2 & Comp3 & Comp4 & Comp5 & Comp6 \\
\hline w01ROAp & 0.7105 & & & & & \\
\hline w01ROEp & 0.6817 & & & & & \\
\hline w01RzRecOp p & & 0.7073 & & & & \\
\hline w01RzDespO $\sim p$ & & -0.7029 & & & & \\
\hline w01Ativoto $\sim \mathrm{p}$ & & & 0.6577 & & & \\
\hline w01RzRecAp p & & & 0.6336 & & & \\
\hline w01RzDepos $\sim p$ & & & & -0.6889 & & \\
\hline w01RzCre stp & & & & 0.6913 & & \\
\hline w01CrescOp p & & & & & 0.6864 & \\
\hline w01CrescAt $\sim p$ & & & & & 0.6741 & \\
\hline w01RzProvi p & & & & & & 0.5222 \\
\hline w01FluxoCe $\sim p$ & & & & & & -0.7482 \\
\hline
\end{tabular}

Fonte: Elaborada pelos autores

Desta última solução fatorial, faz-se possível extrair um conjunto de fatores passíveis de interpretação no contex to dos bancos atuantes no mercado de cessões de direitos creditórios.

Componente 1: No primeiro componente estão alocadas duas medidas padrão para análise do desempenho operacional das instituições, em função de seus retornos. Sendo medidas básicas da lucratividade de um empreendimento em relação aos seus investimentos, os retornos sobre os ativos (ROA) e sobre o patrimônio líquido (ROE) são confirmados como indicadores importantes na avaliação do desempenho operacional dos bancos. No contexto da cessão de créditos, tais medidas servem, sobretudo, para mensurar o nível de desempenho operacional dos bancos que atuam no mercado de cessões, conforme já demonstrado no trabalho de Casu et al. (2013, p. 1647)

Componente 2: o segundo componente diz respeito à proporção de receitas e despesas operacionais não relacionadas à intermediação financeira em relação ao resultado operacional dos bancos. Tais variáveis permitem a análise de quanto do resultado das instituições participantes no mercado secundário de crédito é afetado por atividades não relacionadas à atividade básica de intermediação. Considerando que a atuação no mercado de cessões é apontada na literatura também como forma de diversificação das atividades bancárias 
Cessões de direitos creditórios dos bancos brasileiros: análise exploratória do impacto no desempenho operacional e financeiro

(AFFINITO; TAGLIAFERRI, 2010, p. 191), cabe, nesse contexto, a utilização de um componente que aborde justamente em que grau isso se reflete no resultado das instituições. Dessa forma, pode-se avaliar quanto das receitas são auferidas e quanto das despesas são incorridas de forma não diretamente relacionada com a intermediação financeira em bancos atuantes no mercado de cessão.

Componente 3: Ativos totais e a razão das Receitas de Aplicações Compulsórias sobre o Total das Receitas de Intermediação Financeira estão agrupadas no componente 3. Uma possível explicação para isso está relacionada a quais os tipos de aplicações compulsórias hoje determinadas pelo Banco Central do Brasil e o porte dos bancos. Parte relevante dessas aplicações são constituídas, atualmente, de operações de crédito rural e de créditos vinculados ao Sistema Financeiro de Habitação. Por sua vez, os maiores operadores desses tipos de operações de crédito no Brasil são também dois dos maiores bancos em ativos totais no Brasil: O Banco do Brasil S.A. e a Caixa Econômica Federal. Ademais, Certificados de Recebíveis Imobiliários e Certificados de Recebíveis do Agronegócio estão entre os três tipos mais comuns de ativos do mercado de securitização.

Componente 4: o quarto componente reúne as variáveis Depósito Total e o índice constituído pela razão entre o total das operações de crédito e arrendamento mercantil sobre o Depósito Total. Cabe reiterar a importância desses indicadores frente os determinantes das cessões de direitos creditórios já estabelecidos na literatura. A decisão bancária de ceder parcela de sua carteira está diretamente relacionada com sua capacidade de financiar novas operações de crédito por meio de depósitos (PENNACCHI, 1988, p. 376). Tais variáveis, portanto, medem a capacidade de os bancos originarem novas operações de crédito com base em recursos captados de terceiros.

Componente 5: As taxas de crescimento de ativos totais e de operações de crédito formam o quinto componente. Ambas são indicadores importantes das necessidades de liquidez das instituições bancárias. O crescimento da carteira de crédito pressupõe que os bancos disponham do caixa necessário para a realização de novas concessões (CASU ET AL., 2013, p. 1638). Da perspectiva do crescimento dos ativos, tal situação significa o mesmo que considerar que eventuais excessos de liquidez no mercado induzem maior oferta de crédito. Dessa forma, tal componente induz à avaliação de como a liquidez dos bancos participantes no mercado de cessões está relacionada com o crescimento de seus ativos e, consequentemente, com sua capacidade de originar novas operações de crédito.

Componente 6: o sexto componente agrega duas variáveis que, em conjunto, refletem o segundo motivo mais comumente apontado na literatura para as cessões de crédito: considerações quanto à gestão do risco dos ativos cedidos (CARLSTROM; SAMOLYK, 1995, p. 628; HAUBRICH; THOMSON, 1996, p. 140). De acordo com a regulamentação financeira em vigor, o volume de provisões para créditos de liquidação duvidosa está diretamente relacionado ao nível de risco das operações. Uma das principais formas de gerenciar requerimentos demasiadamente elevados de provisionamento é justamente a cessão de créditos com perfil de risco elevado, dada a possibilidade de os bancos retirarem tais ativos do balanço, impactando negativamente suas provisões.

Dessa forma, extrai-se da Análise de Componentes Principais efetuada um conjunto de 6 indicadores - neste caso representados por 12 variáveis - passíveis de exploração no desenvolvimento de modelos funcionais relacionados com a cessão de direitos creditórios. Conceitualmente, tais indicadores podem ser definidos como: Desempenho Operacional, Composição das Receitas não Operacionais, Tipos de Ativos Cedidos, Capacidade de Financiamento via Depósitos, Necessidades de Liquidez e Risco da Carteira de Crédito, correspondendo, respectivamente, aos componentes 1 a 6 . 


\section{Considerações Finais}

A evolução do mercado de cessões de direitos creditórios é tema relevante para pesquisa no Brasil não somente pelo aumento no volume dessas operações em âmbito nacional em período recente, mas, também, pela forma como as cessões podem ser utilizadas para gestão do risco das carteiras de crédito bancárias.

Neste trabalho, buscou-se verificar, empiricamente, com base em ampla base de dados referente ao setor bancário nacional, as principais variáveis que, tanto à luz da perspectiva teórica clássica quanto da de trabalhos empíricos empreendidos em âmbito internacional, poderão servir de insumo para futuras análises da relação entre a participação dos bancos brasileiros no mercado de cessões de direitos creditórios e o desempenho operacional e financeiro dessas instituições.

Por meio de uma Análise de Componentes Principais, foram identificados seis possíveis indicadores para avaliação do desempenho de instituições bancárias atuantes no mercado de cessão de direitos creditórios, quais sejam, Desempenho Operacional, Composição das Receitas não Operacionais, Tipos de Ativos Cedidos, Capacidade de Financiamento via Depósitos, Necessidades de Liquidez e Risco da Carteira de Crédito.

Entre as limitações do estudo, está o número de variáveis utilizadas. Embora o principal desafio da pesquisa fosse a redução de dados de uma forma que resultasse em construtos significativos, certamente há, ainda, uma série de outros índices que não puderam ser incluídos no presente estudo, sobretudo pelo fato de que parte dos dados que demonstram os impactos econômico-financeiros das cessões de direitos creditórios nos bancos não são de acesso público. Outros indicadores podem, portanto, vir a ser relevantes sob perspectivas não abordadas no presente texto.

Ademais, ainda que se faça importante reiterar o intuito exploratório da pesquisa, limitou-se aqui apenas ao apontamento, com base nos dados disponíveis, de variáveis potencialmente úteis para o aprofundamento de estudos sobre as cessões de direitos creditórios e o desempenho bancário. Eventuais correlações ou efeitos causais entre tais fatores não foram exploradas e, portanto, nenhuma conclusão nesse sentido pode ser extraída com base apenas no exposto.

Todavia, considerando a escassez de literatura prévia que tivesse buscado quantificar os impactos das cessões de direitos creditórios, este trabalho apresenta uma proposta consistente para suprir lacuna em relação a algo que nenhum estudo correlacional futuro pode prescindir, que é a definição das variáveis. Para tanto, esta pesquisa oferece construtos significativos e com fundamento teórico e empírico, sendo que tal contribuição não se reveste de utilidade somente para o meio acadêmico. Faz-se importante também que o regulador e supervisor bancário nacional, o Banco Central do Brasil, possa dispor do maior número possível de subsídios para o monitoramento dos bancos sob sua fiscalização, e que investidores mais qualificados, capazes de aprofundar suas avaliações quanto às empresas de capital aberto, tenham o maior número possível de informações para embasamento de suas decisões.

\section{Referências}

AFFINITO, Massimiliano; TAGLIAFERRI, Edoardo. Why Do (or Did?) Banks Securitize Their Loans? Evidence from Italy. Journal of Financial Stability, v. 6, p. 189-202, 2010. Disponível em: <http://dx.doi.org/10.1016/j.jfs.2010.01.004>. Acesso em: 31 mar. 2016. 
AFIFI, Abdelmonem; MAY, Susanne; CLARK, Virginia A. Practical Multivariate Analysis. Fifth ed. Boca Raton: CRC Press, 2012.

AHN, Jung Hyun; BRETON, Régis. Securitization, competition and monitoring. Journal of Banking and Finance, v. 40, n. 1, p. 195-210, 2014. Disponível em: $<$ http://dx.doi.org/10.1016/j.jbankfin.2013.11.023>. Acesso em: 31 mar. 2016.

ALTMAN, Edward I.; GANDE, Amar; SAUNDERS, Anthony. Bank debt versus bond debt: Evidence from secondary market prices. Journal of Money, Credit and Banking, v. 42, n. 4, p. 755-767, 2010. <http://dx.doi.org/10.1111/j.1538-4616.2010.00306.x $>$. Acesso em: 27 out. 2016.

BEDENDO, Mascia; BRUNO, Brunella. Credit risk transfer in U.S. commercial banks: What changed during the 2007-2009 crisis? Journal of Banking and Finance, v. 36, n. 12, p. 3260 3273, 2012. Disponível em: <http://dx.doi.org/10.1016/j.jbankfin.2012.07.011>. Acesso em: 27 out. 2016.

CANBAS, Serpil; CABUK, Altan; KILIC, Suleyman Bilgin. Prediction of commercial bank failure via multivariate statistical analysis of financial structures: The Turkish case. European Journal of Operational Research, v. 166, n. 2, p. 528-546, 2005. Disponível em: $<$ http://doi.org/10.1016/j.ejor.2004.03.023>. Acesso em: 21 abr. 2016.

CARDONE-RIPORTELLA, Clara; SAMANIEGO-MEDINA, Reyes; TRUJILLO-PONCE, Antonio. What drives bank securitisation? The Spanish experience. Journal of Banking and Finance, v. 34, n. 11, p. 2639-2651, 2010. Disponível em:

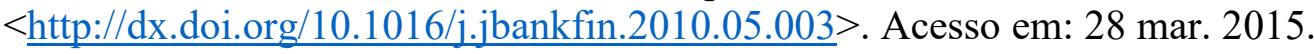

CARLSTROM, Charles T.; SAMOLYK, Katherine a. Loan sales as a response to market-based capital constraints. Journal of Banking \& Finance, v. 19, n. 3-4, p. 627-646, 1995. Disponível em: <http://www.sciencedirect.com/science/article/pii/037842669400144R>. Acesso em: 29 set. 2015 .

CASU, BARBARA et al. Securitization and Bank Performance. Journal of Money, Credit and Banking, v. 45, n. 8, p. 1617-1658, dez. 2013. Disponível em: $<$ http://doi.wiley.com/10.1111/jmcb.12064>. Acesso em: 24 set. 2015.

CHAMPAGNE, Claudia; COGGINS, Frank. Common information asymmetry factors in syndicated loan structures. Journal of Banking and Finance, v. 36, n. 5, p. 1437-1451, 2012.

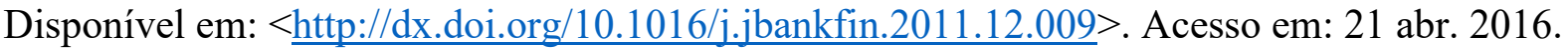

CREEL, Jérôme; HUBERT, Paul; LABONDANCE, Fabien. Financial stability and economic performance. Economic Modelling, v. 48, p. 25-40, 2014. Disponível em: $<$ http://doi.org/10.1016/j.econmod.2014.10.025>. Acesso em: 21 abr. 2016.

BRASIL. Banco Central do Brasil - BCB. 50 maiores bancos e o consolidado do Sistema Financeiro Nacional, 2015a. Disponível em: http://www4.bcb.gov.br/top50/port/top50.asp. 
BRASIL. Banco Central do Brasil - BCB. Relatório de Estabilidade Financeira: out. $2015 b$. Disponível em: < $<$ http://www.bcb.gov.br/?RELESTAB201510>.

BRASIL. Conselho Monetário Nacional - CMN. Resolução $\mathrm{n}^{0}$ 3.533. Estabelece procedimentos para classificação, registro contábil e divulgação de operações de venda ou de transferência de ativos financeiros, jan. 2008. Disponível em: $<$ http://www.bcb.gov.br/pre/normativos/busca/normativo.asp?numero=3533\&tipo=Resolu\%C 3\%A7\%C3\%A3o\&data=31/01/2008>. Acesso em: 7 jun 2015.

DAHIYA, Sandeep; PURI, Manju; SAUNDERS, Anthony. Bank Borrowers and Loan Sales: New Evidence on the Uniqueness of Bank Loans. The Journal of Business, v. 76, n. 4, p. 563 582, 2003. Disponível em: <http://doi.org/10.1086/377031>. Acesso em: 28 set. 2015.

DEMSETZ, Rebecca S. Bank loan sales: a new look at the motivations for secondary market activity. The Journal of Financial Research, v. XXIII, n. 2, p. 197-222, 2000. Disponível em:

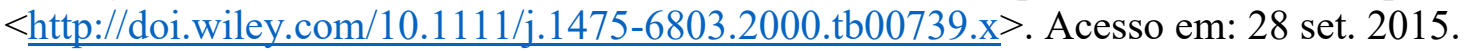

DRUCKER, Steven; PURI, Manju. On loan sales, loan contracting, and lending relationships. The Review of Financial Studies, v. 22, n. 7, p. 2635-2672, 2009. Disponível em: $<$ http://doi.org/10.1093/rfs/hhn067>. Acesso em: 28 set. 2015.

FARRUGGIO, Christian; UHDE, André. Determinants of loan securitization in European banking. Journal of Banking and Finance, v. 56, p. 12-27, 2015. Disponível em: $<$ http://dx.doi.org/10.1016/j.jbankfin.2015.01.015>. Acesso em: 20 abr. 2016.

GANDE, Amar; SAUNDERS, Anthony. Are Banks Still Special When There Is a Secondary Market for Loans? Journal of Finance, v. 67, n. 5, p. 1649-1684, 2012. Disponível em:

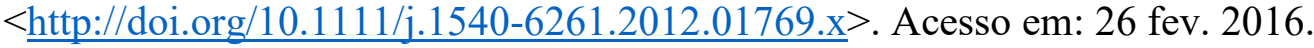

GORTON, Gary B.; PENNACCHI, George G. Banks and loan sales: marketing nonmarketable assets. Journal of Monetary Economics, v. 35, p. 389-411, 1995. Disponível em: $<$ http://dx.doi.org/10.1016/0304-3932(95)01199-X>. Acesso em: 10 set. 2015.

GREENBAUM, Stuart I.; THAKOR, Anjan V. Bank Funding Modes: Securitization versus Deposits. Journal of Banking and Finance, v. 11, p. 379-401, 1987. Disponível em: < doi:10.1016/0378-4266(87)90040-9>. Acesso em: 8 mar. 2016.

HAN, Joongho; PARK, Kwangwoo; PENNACCHI, George. Corporate Taxes and Securitization. The Journal of Finance, v. 70, n. 3, p. 1287-1321, 2015. Disponível em: $<$ http://doi.wiley.com/10.1111/jofi.12157>. Acesso em: 16 nov. 2015.

HAUBRICH, Joseph G.; THOMSON, James B. Loan Sales, Implicit Contracts, and Bank Structure. Review of Quantitative Finance and Accounting, v. 7, p. 137-162, 1996. Disponível em: <http://link.springer.com/10.1007/BF00243975>. Acesso em: 6 nov. 2015.

JAMES, Christopher. The use of loan sales and standby letters of credit by commercial banks. Journal of Monetary Economics, v. 22, n. 3, p. 395-422, 1988. Disponível em: $<$ http://doi.org/10.1016/0304-3932(88)90005-0>. Acesso em: 16 nov. 2015. 
KEYNES, John Maynard. A Teoria Geral do Emprego, do Juro e da Moeda. São Paulo: Nova Cultural, 1996.

KLOMP, Jeroen; HAAN, Jakob De. Banking risk and regulation: Does one size fit all? Journal of Banking and Finance, v. 36, n. 12, p. 3197-3212, 2012. Disponível em:

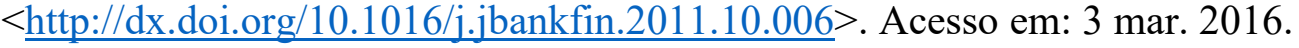

PARLOUR, Christine a.; PLANTIN, Guillaume. Loan sales and relationship banking. Journal of Finance, v. 63, n. 3, p. 1291-1314, 2008. Disponível em: <http://doi.org/10.1111/j.15406261.2008.01358.x>. Acesso em: 2 set. 2015.

PARLOUR, Christine a.; WINTON, Andrew. Laying off credit risk: Loan sales versus credit default swaps. Journal of Financial Economics, v. 107, n. 1, p. 25-45, 2013. Disponível em: $<$ http://dx.doi.org/10.1016/j.jfineco.2012.08.004>. Acesso em: 29 set 2015.

PAVEL, C.; PHILIS, D. Why commercial banks sell loans: An empirical analysis. Federal Reserve Bank of Chicago Economic Perspectives, v. 14, p. 3-14, 1987. Disponível em: $<$ https://www.chicagofed.org/publications/economic-perspectives/1987/07mayjun1987-part1pavel>. Acesso em: 9 mar. 2016.

PENNACCHI, George G. Loan Sales and the Cost of Bank Capital. The Journal of Finance, v. 43, n. 2, p. 375-396, jun. 1988. Disponível em: <http://doi.org/10.2307/2328466>. Acesso em: 18 abr. 2016.

RIBEIRO, Fernanda Vieira Fernandes; SCHIOZER, Rafael Felipe. Cessão de Crédito e Restrição De Capital: Um estudo com bancos brasileiros. Revista de Administração de Empresas, v. 54, n. 5, p. 521-536, 2014. Disponível em: <http://dx.doi.org/10.1590/S0034759020140506>. Acesso em: 24 set. 2015.

SHIH, Victor; ZHANG, Qi; LIU, Mingxing. Comparing the performance of Chinese banks: A principal component approach. China Economic Review, v. 18, n. 1, p. 15-34, 2007.

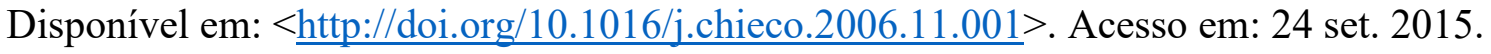

Versão prévia (preprint) do artigo foi apresentada no XL Encontro da Associação Nacional de Pós-Graduação e Pesquisa em Administração (EnANPAD) em setembro de 2016. 